\title{
COMPARISON OF ARTERIAL BLOOD GAS ANALYSIS VERSUS CENTRAL LABORATORY ELECTROLYTE AND HEMOGLOBIN DETERMINATION IN BIRAT MEDICAL COLLEGE AND TEACHING HOSPITAL
}

\author{
Arjyal $B^{1^{*}}$, Rajbanshi $L K^{2}$, Khanal $K^{3}$, Bajracharya $A^{1}$
}

\section{Affiliation}

1. Lecturer, Department of Anesthesia and Critical care, Birat Medical College and Teaching Hospital.

2. Associate professor, Department of Anesthesia and Critical care, Birat Medical College and Teaching Hospital.

3. Consultant Anesthesiologist,Department of Anesthesia and Critical care, Birat Medical College and Teaching Hospital.

\section{ARTICLE INFO}

Received : 09 February, 2020

Accepted : 18 March, 2020

Published : 30 June, 2020

(C) Authors retain copyright and grant the journal right of first publication with the work simultaneously licensed under Creative Commons Attribution License CC - BY 4.0 that allows others to share the work with an acknowledgment of the work's authorship and initial publication in this journal.

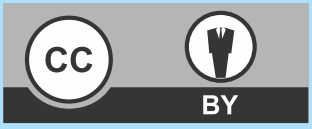

\section{ORA 165}

DOI: https://doi.org/10.3126/bjhs.v5i1.29634

\section{* Corresponding Author \\ Dr. Batsalya Arjyal \\ Lecturer}

Department of Anesthesiology and Critical Care Birat Medical College and Teaching Hospital, Biratnagar Email ID: batsalyaarjyal@gmail.com

ORCID ID: https://orcid.org/0000-0001-6939-4554

\section{Citation}

Arjyal B, Rajbanshi LK, Khanal K, Bajracharya A. Comparison of Arterial blood gas analysis versus Central Laboratory Electrolyte and Hemoglobin determination in Birat Medical College and Teaching Hospital. BJHS 2020;5(1)11: 960-963.

\section{ABSTRACT}

\section{Introduction}

Electrolyte and hemoglobin measurement are the integral part of management of critically ill patient. There can be a wide variation in the electrolyte and hemoglobin measurement in critically ill patient between arterial blood gas analyzer and central laboratory auto analyzer.

\section{Objective}

To compare the electrolytes (sodium, potassium and chloride) and hemoglobin level measured by arterial blood gas analyzer and laboratory analyzer.

\section{Methodology}

This was a prospective cross-sectional comparative study comparing the electrolytes (sodium, potassium and chloride) and hemoglobin measurement between arterial blood gas analyzer and laboratory auto analyzer. The study included 124 paired blood samples from the patient admitted in intensive care unit of Birat Medical College Teaching Hospital in two months duration. The arterial sample and venous sample for electrolytes and hemoglobin measurement were taken simultaneously or not more than one hour apart and analysis was done by arterial blood gas analyzer and central laboratory auto analyzer accordingly. The values of electrolytes and hemoglobin measured by two different analyzers were finally compared for variation.

\section{Result}

The mean difference calculated for sodium potassium and chloride in $A B G$ machine and Auto-analyzers were 0.57 $\mathrm{mmol} / \mathrm{l} .-0.04 \mathrm{mmol} / \mathrm{l}$ and $1.71 \mathrm{mmol} / \mathrm{l}$ respectively. These data were within the acceptable range of United States Clinical Laboratory Improvement Amendments(USCLIA). The mean difference derived for hemoglobin in $A B G$ and Auto-analyzers was $0.16 \mathrm{~g} / \mathrm{dl}$ which was not consistent with the range of United States Clinical Laboratory Improvement Amendments (USCLIA)

\section{Conclusion}

The measurement of electrolyte namely sodium, potassium and chloride in ABG machines and Auto-analyzers of central lab were comparable while hemoglobin was not comparable under the USCLIA guidelines.

\section{KEY WORDS}

Auto-analyzers, ABG machine,chloride, hemoglobin, potassium, sodium. 


\section{INTRODUCTION}

Electrolyte imbalance is the common clinical and laboratory abnormality in critically ill patient. ${ }^{1}$ Unnoticed or undiagnosed electrical abnormalities can increase the morbidity and mortality in critically ill patients. Therefore, these electrolytes are very important in determining the outcome of critically ill patient ${ }^{2}$

Most of the major electrolytes including sodium, potassium and chloride can be measured by Arterial Blood Gas analyzer. Besides, hemoglobin and hematocrit can also be measured as a point of care test by ABG machine. ${ }^{3}$ Though ABG has become a gold standard in ICU setup, electrolytes and hemoglobin are being sent on a regular basis to the laboratory despite the time lag. However, when processed by a central laboratory the results are delayed by a few hours that can affect the clinical management of the critically ill patients. ${ }^{4}$ This delay in reporting time does not allow the clinician to correct the electrolyte abnormality or anemia promptly, hence hindering the improvement of the patient.

ABG analyzer measures electrolytes by direct ion-selective electrolyte method and uses undiluted sample while central laboratory auto analyzer measures the electrolyte by indirect ion-selective electrolyte method and uses diluted samples. ${ }^{5}$ Besides, ABG analyzer uses whole blood and takes shorter processing time while laboratory auto analyzers use serum blood and take longer time. ${ }^{6}$ These two fact can lead to the discrepancy in the values measured by the two analyzers.

ABG machines are primarily designed to analyze the blood gas parameters and not for the electrolytes or hemoglobin. Though ABG machine provides a point of care testing for electrolyte measurement, the change in $\mathrm{pH}$ can lead to variable degree of membrane permeability which in turn leads to displacement of electrolyte. Thus, the variable effect of $\mathrm{pH}$ in the electrolyte displacement specifically potassium can contribute to the unreliability of electrolyte measurement by ABG machine. ${ }^{7}$ Many times clinicians prefer to measure the electrolytes and confirm in the central laboratory by Auto-analyzer.Moreover, there have been numerous studies which have shown that $A B G$ measurements have not been consistent with central laboratories in hospital even with the same sample. ${ }^{8}$

There is a wide disparity in the literature regarding recommendation for electrolytes measurement by $A B G$ and laboratory auto analyzer without any conclusive recommendation. Thus, this study had been designed to enrich the data bank and access the reliability of electrolytes and hemoglobin measurement by ABG machine. The study compared the differences in the measurement of three major electrolytes sodium, potassium and chloride with additional hemoglobin measurement between $A B G$ machine as a point of care testing and laboratory Autoanalyzer in the critically ill patients in the intensive care unit of Birat Medical College and teaching hospital.

\section{METHODOLOGY}

This was a comparative prospective study conducted in patients admitted between15-6-2019 to 15-8-2019 in critical care unit of Birat Medical College and Teaching Hospital. All the blood samples that were sent for ABG analysis and central laboratory, during this period of time, were included in the study. The samples which had error in sampling techniques were not included in the study. A total of 124 paired blood samples from critically ill patients in ICU were included in the study for electrolyte and hemoglobin analysis by $A B G$ machine ( $A B L$ flex 80 ) in ICU and Autoanalyzer (Medonic $M$ series in central laboratory of Birat Medical College and teaching hospital).

Under all the aseptic precautions an ABG sample of $1 \mathrm{ml}$ of blood was collected in a pre-heparinized BD (Bacton Dickson) syringes. This arterial sample collected for $A B G$ was processed in $A B L$ flex 80 analyzer to draw the values of electrolytes and hemoglobin. Simultaneously another venous sample of 4-5 $\mathrm{ml}$ of blood was extracted of which 1 $\mathrm{ml}$ was transferred to an EDTA tube (levacvacutainer) for complete blood count reporting and next $2 \mathrm{ml}$ of blood was transferred to other levacvacutainer for electrolytes. These samples were drawn by trained health care professionals. Thesevenous samples were sent to laboratory for further evaluation. The blood sample collected in an EDTA tube for $\mathrm{CBC}$ (complete blood count) was directly analyzed in Autoanalyzer (Medonic M series) while, the blood sample collected in the vacutainer for serum electrolytes was centrifuged for 5 minutes before being analyzed in Humalyte plus 3.The Auto-analyzers and the ABG analyzer were calibrated each time a new reagent was installed. This was done for quality control.

The values of electrolytes and hemoglobin obtained from $A B G$ and central laboratory auto analyzer were saved in Microsoft excel. Statistical analysis was done by IBM SPSS version 23.The continuous data were used for analyzing the mean and standard deviation, while student $t$ test was used to compare the data between $A A$ and $A B G$. The $p$ value $<0.05$ was considered to be significant.

The accepted level of variation among the two groups was considered according to US-CLIA (United States Clinical Laboratory Improvement Amendments) guidelines. The guideline accepts differences as; sodium $\pm 4.0 \mathrm{mmol} /$ L,potassium $\pm 0.5 \mathrm{mmol} / \mathrm{L}$, chloride $\pm 5 \mathrm{mmol} / \mathrm{l}$; hemoglobin $\pm 7 \%$ compared to the target values. $^{5}$

\section{RESULTS}

Table 1. Electrolyte and hemoglobin in Arterial blood gas and Auto analyzer

\begin{tabular}{|l|c|c|c|c|}
\hline & $\begin{array}{c}\text { Arterial blood } \\
\text { gas }\end{array}$ & $\begin{array}{c}\text { Auto analyzer } \\
\text { (Central lab) }\end{array}$ & P value & $\begin{array}{c}\text { Mean } \\
\text { difference }\end{array}$ \\
\hline $\begin{array}{l}\text { Sodium } \\
\mathrm{n} \pm \text { SD mmol/l }\end{array}$ & $140.63 \pm 8.08$ & $140.06 \pm 7.54$ & 0.00 & 0.57 \\
\hline $\begin{array}{l}\text { Potassium } \\
\mathrm{n} \pm \text { SD mmol/l }\end{array}$ & $4.08 \pm 0.75$ & $4.12 \pm 0.71$ & 0.00 & -0.04 \\
\hline $\begin{array}{l}\text { Chloride } \\
\mathrm{n} \pm \text { SD mmol/l }\end{array}$ & $104.61 \pm 6.61$ & $102.9 \pm 6.62$ & 0.00 & 1.71 \\
\hline $\begin{array}{l}\text { Hemoglobin } \\
\mathrm{n} \pm \text { SD g/dl }\end{array}$ & $10.47 \pm 2.64$ & $10.31 \pm 2.72$ & 0.00 & 0.16 \\
\hline
\end{tabular}


The analysis of sodium values (table 1 ) showed that mean sodium in ABG was140.63 $\pm 8.08 \mathrm{mmol} / \mathrm{l}$ and the mean sodium in auto analyzer was $140.06 \pm 7.54$. The mean difference in sodium level was $0.57 \mathrm{mmol} / \mathrm{I}$ (SD-0.51 mmol/I). When the mean sodium level was evaluated for $A B G$ and autoanalyzer, a significant difference was evident $(p<0.05)$.

The mean potassium level measured inABG was $4.08 \pm 0.75$ $\mathrm{mmol} / \mathrm{I}$ while the value in autoanalyzer was $4.12 \pm 0.71 \mathrm{mmol} / \mathrm{I}$ (table 1). The mean difference in potassium level was 0.04 $\mathrm{mmol} / \mathrm{I}(\mathrm{SD}-3881 \mathrm{mmol} / \mathrm{l})$.A significant difference was evident $(p<0.05)$ when mean value for potassium was observed.

The evaluation of chloride value (table1) showed that mean chloride in ABG was $104.61 \pm 6.61 \mathrm{mmol} / \mathrm{l}$ and the mean chloride in auto analyzer was $102.9 \pm 6.62 \mathrm{mmol} / \mathrm{l}$. The mean difference in chloride level was $1.71 \mathrm{mmol} / \mathrm{I}$ (SD- 0.45 $\mathrm{mmol} / \mathrm{I})$. When mean chloride level was evaluated for $A B G$ and $A A$ a significant difference was evident $(p<0.05)$.

The mean hemoglobin level (table 1) measured in ABG was $10.47 \pm 2.64 \mathrm{gm} / \mathrm{dl}$ while the value in autoanalyzer was $10.31 \pm 2.72 \mathrm{~g} / \mathrm{dl}$. The mean difference in hemoglobin level was $0.16 \mathrm{~g} / \mathrm{dl}$ (SD-0.08g/dl). A significant difference was evident $(p<0.05)$ when mean value for hemoglobin was observed.

\section{DISCUSSION}

As electrolyte abnormality is a frequent clinical condition in critically ill patient, early detection and early management of this reversible changes is very important. Initiating early treatment in such conditions benefit the patient clinically and also decreases the economic burden. ${ }^{9}$

The present study showed that the mean difference of sodium in $A B G$ and $A A$ was $0.57 \mathrm{mmol} / \mathrm{l}$. This is within the acceptable range of USCLIA as discussed earlier. There are 7 values( $<6 \%$ ) of sodium during the comparison in our study, which did not fall in USCLIA guidelines. The reason behind this inappropriate report might be due to hypoalbuminemia, which was not evaluated in our study. The overestimation of sodium in indirect ion selective electrodes method was reported by Shalini G et al. to be linked with serum protein and albumin. It was further stated that, this could be the cause of overestimation of sodium in hypoalbuminemia by Auto-analyzers. $^{5}$

Zhang JB et al. from their study concluded that the meanbias of sodium and potassium in ABG was comparable to that of Auto analyzers. ${ }^{10 .}$ In a study conducted on 352 patients by Gibson $\mathrm{M}$ et al. it was agreed that $>95 \%$ sodium values was comparable between $A B G$ and $A A$ agreeing to accept the reports to make decisions in critical care setting. ${ }^{11}$

A large study was conducted in supramaximal care hospital to evaluate the accuracy of point of care machines by Dolscheid-Pommerich, R.C. et al. It was noted that there is no inconsistency in the reports of sodium. Despite which it was concluded that further evaluation is required for the ABG machine, since they did not take albumin and protein into consideration. ${ }^{12}$

In the present study, difference for mean of potassium between $A B G$ and $A A$ was measured to be $-0.04 \mathrm{mmol} / \mathrm{I}$.This is within the range of CLIA. In a study conducted on 200 samples by Anunaya Jain et al. it was stated that the potassium value of $A B G$ machine correlated with that of Auto-analyzers (Central laboratory). Since the mean difference in all the conditions namely hypokalemia, normokalemia and hyperkalemia was within the CLIA limits, it was suggested that ABG machine could be trusted for the early intervention by the medical professional. ${ }^{8}$

Shivesh Prakash and his colleagues after conducting similar study agreed that the concordance was moderate to substantial. It was also suggested that except for potassium, result of the other electrolytes in two tests should not be interchanged. ${ }^{13}$

The result of the comparison of potassium level measured by two auto analyzer in our study was supported by the previously published studies ${ }^{7,14}$ except for $Y \cup$ Budak et al. ${ }^{15}$ who disagreed and concluded that the data was notinter changeable.

After finding weak correlation with chloride and none for potassium, Jérôme Allardet - Serventet al. concluded that chloride and potassium are least affected by hypoalbuminemia. They also noted that measuring chloride by the two techniques do not show any difference. ${ }^{16}$

In the present study mean difference in chloride for the test was $1.71 \mathrm{mmol} / \mathrm{I}$.This difference was within the limits of CLIA.

Usyal E et al in their study concluded that despite sodium and potassium having strong correlation, chloride had moderate coorelation. ${ }^{17}$ While Begs $A$ and his colleagues suggested that $A B G$ is a reliable option to analyze chloride along with sodium potassium and hemoglobin. ${ }^{18}$

The mean difference calculated for hemoglobin for ABG and auto analyzerin our study was 0.16 . This value does not match with the limits provided by CLIA. This result was consistent with the one conducted by Gavala A and his colleagues, who concluded that the hemoglobin level measured by $A B G$ analyzer was lower as compared to the central autoanalyzer. ${ }^{19} \mathrm{~A}$ study conducted by Leino $\mathrm{A}$ and Kurvinen $\mathrm{K}$ stated that hemoglobin was incomparable between the two analyzers. They concluded that in a clinical condition where hemoglobin was low, it over diagnosed anemia $^{20}$. This discrepancy was well explained by Jérôme Allardet-Servent et al. who considered the confounding factors like cell fragments from incomplete hemolysis and high bilirubin level and high lipid fractions and the method of analysis. ${ }^{16}$

Triplet K E et al. concluded that, there was no significant difference in the hemoglobin values measured by the two analyzers (Auto Analyzer and Arterial Blood gas), suggesting that it is not necessary to send concurrent samples to $A B G$ and auto analyzers in central laboratory. ${ }^{21}$

\section{CONCLUSION}

The sodium, potassium and chloride values measured by the arterial blood gas analyzer were comparable with the values obtained by the laboratory autoanalyzer and thus the 
arterial blood gas analyzer could be considered as a point of care testing in ICU for the electrolyte measurement. However, the hemoglobin level measured by arterial blood gas analyzer was not comparable with that measured by laboratory auto-analyzer. Hence, we conclude that arterial blood gas analyzer could be not used as a point of care testing for hemoglobin.

\section{LIMITATIONS OF THE STUDY}

Factors like arterial and venous blood, serum and whole blood for analysis of electrolytes and hemoglobin were not considered to nullify the potential effect of these factors on the result of the study. The pre-analytic factors like two different pricks to procure the sample, sample handling, the time frame required in analyzing the sample in central laboratory were not assessed. We also did not take into account the protein and albumin of the patient which could be the cause of some unexpected values as discussed.

\section{FINANCIAL DISCLOSURE}

None

\section{ACKNOWLEDGMENT}

We would like to thank all the participants, paramedics, nursing staffs and medical officers of ICU for helping us in collecting samples and data. We would like to specially thank Dr. Tara Kafle who helped us in statistical analysis. We would also like to thank Prof Dr. Nabraj koirala for educating us and supporting us morally during the preparation of this manuscript.

\section{REFERENCES (Style of referencing should be in Vancouver.)}

1. Sinan Yılmaz, MD, Hilal B. Uysal, MD, MücahitAvcil, MD, Mustafa Yılmaz, MD, BekirDağlı, MD, Murat Bakış, MD, and Imran K. Ömürlü, PhD.Comparison of different methods for measurement of electrolytes in patients admitted to the intensive care unit.Saudi Med J. 2016 Mar; 37(3): 262-267.doi: 10.15537/smj.2016.3.13539. PMCID: PMC4800889.PMID: 26905347

2. Nanda SK, Ray L, Dinakaran A. Agreement of arterial sodium and arterial potassium levels with venous sodium and venous potassium in patients admitted to intensive care unit [published correction appears in J Clin Diagn Res. 2015 Nov;9(11):ZZ01]. J Clin Diagn Res. 2015;9(2):BC28-BC30. doi:10.7860/JCDR/2015/12418.5602

3. Lee-Lewandrowski $E$, LewandrowskiK.Perspectives on cost and outcomes for point-of-care testing. Clin Lab Med. 2009 Sep; 29(3): 479-89.

4. Kost GJ, Ehrmeyer SS, Chernow B, Winkelman JW, Zaloga GP, Dellinger $\mathrm{RP}$, Shirey T The laboratory-clinical interface: point-of-care testing. Chest. 1999 Apr; 115(4):1140-54.

5. Shalini Gupta, Ashwani K. Gupta,Kamaljit Singh, and MinniVerma.Are sodium and potassium results on arterial blood gas analyzer equivalent to those on electrolyte analyzer? Indian J Crit Care Med. 2016 Apr; 20(4): 233-237.PMID: 27303138 doi: 10.4103/09725229.180044

6. Pungor $\mathrm{E}$ Working mechanism of ion-selective electrodes. Pure \& Appl. Chem 1992; 64(4):503-507.doi:10.1351/pac19926404050

7. Hohmann, Christopher \&Pfister, Roman \&Kuhr, Kathrin \&Merkle, Julia \&Hinzmann, Julian \&Michels, Guido. (2019). Determination of Electrolytes in Critical Illness Patients at Different pH Ranges: Whom Shall We Believe, the Blood Gas Analysis or the Laboratory Autoanalyzer?. Critical Care Research and Practice. 2019. 1-6. 10.1155/2019/9838706.

8. Jain A, Subhan I, Joshi M. Comparison of the point-of-care blood gas analyzer versus the laboratory auto-analyzer for the measurement of electrolytes. International journal of emergency medicine. 2009; 2(2):117-20. pmid:20157454

9. Price CP. Medical and economic outcomes of point of care testing. Clin Chem Lab Med. 2002;40:246-251. doi: 10.1515/CCLM. 2002. 040.

10. Zhang JB, Lin J, Zhao XD. Analysis of bias in measurements of potassium, sodium and hemoglobin by an emergency department-based blood gas analyzer relative to hospital laboratory autoanalyzer results. PLoS ONE. 2015;10:e0122383.

11. Gibbons M, Klim S, Mantzaris A, Dillon O, Kelly AM. How closely do blood gas electrolytes and hemoglobin agree with serum values in adult emergency department patients: An observational study. Emerg Med Australas. 2019 Apr;31(2):241-246. doi: 10.1111/17426723. 13133. Epub 2018 Jul 19.
12. Prakash S, Bihari S, Lim ZY, Verghese S, Kulkarni H, Bersten AD. Concordance between point-of-care blood gas analysis and laboratory autoanalyzer in measurement of hemoglobin and electrolytes in critically ill patients. J Clin Lab Anal. 2018;32:e22425 10.1002/jcla.22425

13. Dolscheid-Pommerich, R.C., et al. Retrospective Evaluation of the Accuracy of Point of Care Versus Central Laboratory Sodium Measurements at a Supra Maximal Care Hospital. (2018) J Anesth Surg 5(1): 22-40

14. V. Pant, A. Tumbapo, and B. Karki, "Inter-instrumental comparison for the measurement of electrolytes in patients admitted to the intensive care unit," International Journal of General Medicine, vol. 10, pp. 145-149, 2017

15. Y. U. Budak, K. Huysal, and M. Polat, "Use of blood gas analyzer and a laboratory autoanalyzer in routine practice to measure electrolytes in intensive care unit patients," BMC Anesthesiology, vol. 12, no. 1, p. 17, 2012.

16. JérômeAllardet-Servent, et al Point-of-Care Versus Central Laboratory Measurements of Hemoglobin, Hematocrit, Glucose, Bicarbonate and Electrolytes: A Prospective Observational Study in Critically III Patients PMID: 28072822PMCID: PMC5224825doi: 10.1371/ journal. pone.0169593 PLoS One. 2017; 12(1): e0169593.Published online 2017 Jan 10.

17. Uysal E, Acar YA, Kutur A, Cevik E, Salman N, Tezel O. How reliable are electrolyte and metabolite results measured by a blood gas analyzer in the ED?Am J Emerg Med. 2016 Mar;34(3):419-24. doi: 10.1016/j.ajem.2015.11.025. Epub 2015 Nov 26.

18. Beggs, A., Grounds, M., Bennett, D. et al. Comparison of arterial haemoglobin and electrolyte measurements between an arterial blood gas analyser and the laboratory on the critical care unit. CritCare 10, P239 (2006). https://doi.org/10.1186/cc4586

19. Gavala A, Myrianthefs P.Comparison of point-of-care versus central laboratory measurement of hematocrit, hemoglobin, and electrolyte concentrations.doi: 10.1016/j.hrtlng.2017.04.003. Epub 2017 May 3.2017 Jul - Aug;46(4):246-250.

20. Leino A, Kurvinen K: Interchangeability of blood gas, electrolyte and metabolite results measured with point-of-care, blood gas and core laboratory analyzers. Clin Chem Lab Med 2011; 49: 1187-91 10.1515/CCLM.2011.185

21. Triplett KE, Wibrow BA, Norman R, Hince DA, Hardy LE, Tan S, Ho KM, Anstey MH.Can the blood gas analyser results be believed? A prospective multicentre study comparing hemoglobin, sodium and potassium measurements by blood gas analyzers and laboratory auto-analyzers. Anaesth Intensive Care. 2019 Mar;47(2):120-127. doi: 10.1177/0310057X19840046. Epub 2019 May 9. 